\title{
Impact of aerobic exercise on sleep and motor skills in children with autism spectrum disorders - a pilot study
}

This article was published in the following Dove Press journal:

Neuropsychiatric Disease and Treatment

5 August 2015

Number of times this article has been viewed

\author{
Serge Brand ${ }^{1,2, *}$ \\ Stefanie Jossen ${ }^{2, *}$ \\ Edith Holsboer-Trachsler' \\ Uwe Pühse ${ }^{2}$ \\ Markus Gerber ${ }^{2}$ \\ 'Psychiatric Clinics of the University \\ of Basel, Center for Affective, \\ Stress and Sleep Disorders (ZASS), \\ ${ }^{2}$ Department of Sport, Exercise \\ and Health, Sport Science Section, \\ University of Basel, Basel, Switzerland \\ *These authors contributed equally \\ to this work and share the first \\ authorship
}

Background: Prevalence rates of autism spectrum disorder (ASD) have increased dramatically in the last two decades. In addition to the core symptoms such as impaired communication, difficulties in social interaction, and restricted and stereotypical patterns of behavior and interests, poor sleep and motor skill (MS) deficits have also been observed in children with ASD. On the other hand, there is evidence that aerobic exercise training (AET) has a positive impact on sleep, and that specific training improves MSs. Accordingly, the aim of the present pilot study was to investigate to what extent a combination of AET and MS training (MST) would improve sleep and physical performance in a small sample of children with ASD.

Methods: Ten children with ASD (mean age: 10 years) took part in the study. After a thorough medical examination and psychiatric assessment, children participated in thrice-weekly 60-minute sessions of AET and MST lasting for 3 consecutive weeks. Sleep was assessed both objectively (sleep-encephalography [sleep-EEG]) and subjectively (parents' questionnaire). MSs were assessed via standardized test batteries. Parents completed sleep and mood logs, and ratings of mood.

Results: Mild-to-moderate insomnia was reported in $70 \%$ of children. Compared to nights without previous AET and MS, on nights following AET and MS, sleep efficiency increased $(d=1.07)$, sleep onset latency shortened $(d=0.38)$, and wake time after sleep onset decreased for $63 \%$ of the sample $(d=1.09)$, as assessed via sleep-EEG. Mood in the morning, as rated by parents, improved after three weeks ( $d=0.90$ ), as did MSs (ball playing, balance exercise: $d s>0.6$ ).

Conclusion: The pattern of results of this pilot study suggests that regular AET and MST impact positively on sleep, MSs, and mood among children with ASD.

Keywords: physical activity, ball playing, balancing, insomnia, sleep efficiency, autism spectrum disorder, sleep-EEG

\section{Introduction}

There is an agreement within the scientific community that prevalence rates of mental and neurological disorders have increased and have now overtaken those of cardiovascular diseases and cancer. ${ }^{1}$ Here, we focus on autism spectrum disorder (ASD), understood as a neurodevelopmental condition characterized by severe impairment of reciprocal social interactions and communication skills, and the presence of restricted, stereotypical behaviors. ${ }^{2}$ Having ASD affects basic aspects of social behavior (eg, eye contact, vocalization) and attention (to certain kinds of stimuli) and also motivation, which in turn affects learning and opportunities for learning. At least for five reasons, this mental and neurological disorder warrants special attention. First, there are indications that advances in screening and diagnostics are associated with the rising prevalence rates reported of ASD as compared, for instance, with cognitive disability ${ }^{3}$ (for an opposing point of view, refer Baxter ${ }^{4}$ ). Second, it is estimated that, with respect 
to disability-adjusted life years (DALYs; a measurement to assess "the sum of years lost due to premature mortality and years lived with disability adjusted for severity"), autistic disorders account for more than 58 DALYs per 100,000 population, leading to substantial health loss over the life span. ${ }^{4}$ Third, Croen et $\mathrm{l}^{5}$ estimated that, for example, in the USA, treatment of ASD was the most expensive category of special education, and that health care costs were threefold higher for children with ASD than for children with other mental or physical disorders. Fourth, the psychological burden for children with ASD and also for their close caregivers is extremely high. ${ }^{6}$ Fifth, there is a need of both scientific research and practical interventions to improve the sleep $^{7-10}$ and motor skills (MSs) of children with ASD, ${ }^{11-13}$ with research having shown that poor sleep and poor MSs are problems for children with ASD, while poor sleep is also a problem for their caregivers.

The aim of the present study was to investigate the influence of physical activity (PA) on MS, endurance performance, and objective sleep in children with ASD. Therefore, in the next paragraphs, we first explain the importance of sleep in psychological functioning, and we review research on sleep in children with ASD. Next, we explain the influence of PA on sleep. Last, we report the issue of MSs and PA of children with ASD.

With respect to sleep, numerous studies confirm that sufficient and restoring sleep is associated with more favorable psychological functioning; ${ }^{14-16}$ better-quality sleep is associated with better academic, cognitive, emotional, behavioral, and social performance.

In children with ASD, sleep problems are common. First, we note that the occurrence of ASD is associated with poor sleep; Liu et $\mathrm{al}^{7}$ reported that prevalence rates of insomnia range between $40 \%$ and $80 \%,{ }^{17,18}$ while Ming et $\mathrm{al}^{9}$ observed that sleep disorders are among the most prevalent comorbidities in ASD. Not surprisingly, the US National Sleep Foundation identified children with ASD as one of the highest priority populations for sleep research and treatment. ${ }^{19}$ Richdale and Schreck $^{8}$ claimed that about two-thirds of children with ASD develop persisting sleep disorders. Concerning the association between sleep disorders and IQ, Hare et $\mathrm{al}^{20}$ and Cortesi et $\mathrm{al}^{21}$ found higher sleep disturbances to be associated with lower IQ in children with ASD, while Couturier et al ${ }^{22}$ found sleep disturbances among the so-called high-functioning ASD children. Importantly, Cortesi et $\mathrm{al}^{21}$ found that parents of children with ASD reported more impaired motor behavior (agitation, increased restricted and stereotypical behaviors) following a night with severely impaired sleep, compared to nights with more regular sleep. Likewise, Schreck et $\mathrm{al}^{23}$ showed that shortened sleep duration was associated with lower social competences and increased stereotypical behaviors and autistic symptoms, a pattern also observed elsewhere. ${ }^{24}$ Further, Wiggs and Stores ${ }^{25}$ noted that sleep problems among children with ASD persist over time, suggesting therefore that sleep patterns remain relatively stable over time, a pattern also found among healthy 4.5-year-old preschoolers 1 year later, ${ }^{26}$ and as well as in the transition to adolescence. ${ }^{27}$ In summary, among children with ASD, sleep is impaired, remains stably poor, and seems to be one of the most characteristic features of the disorder beyond the core symptoms such as impairment of reciprocal social interactions and communication skills, and the presence of restricted, stereotypical behaviors. One aim of the present pilot study was therefore to investigate to what extent sleep in children with ASD might be improved by means of PA, and more specifically via a combination of aerobic exercise training (AET) and MS training (MST). Accordingly, we hold that the present results might add to the extant literature on sleep research in which, to the best of our knowledge, the influence of PA on sleep in children with ASD has barely been investigated.

With regard to the association between PA and sleep, cross-sectional $^{28-30}$ and longitudinal-interventional studies ${ }^{31}$ have shown that PA has a positive influence on sleep. For example, Kalak et al $^{31}$ observed objectively improved sleep among adolescents following 3 weeks of morning jogging, relative to controls. Studies carried out among older children, ${ }^{32}$ adolescents, ${ }^{33}$ and adults ${ }^{34}$ have shown that acute bouts of PA improved sleep, ${ }^{32}$ that more vigorous exercise led to objectively improved sleep, ${ }^{33}$ and that adult regular exercisers, irrespective of the time of the day at which they exercised, reported better sleep. ${ }^{34,35}$ Most importantly, positive associations between PA and sleep were also found when both PA and sleep were assessed objectively. ${ }^{30,36}$ Further, to our knowledge, Wachob and Lorenzi ${ }^{37}$ were the first to show that among children with ASD, increased physical activity was associated with increased sleep quality. Overall, it is apparent that PA, irrespective of the time of the day at which it is taken, has a positive impact on sleep. The aim of the present study was accordingly to investigate whether physical activity and more specifically AET and MST also have a positive impact on the sleep of children with ASD.

In addition to the core symptoms of ASD, MS deficits are frequently observed in children with this disorder, ${ }^{38}$ with impairments ranging from 9.9\% (borderline impairments) to $72 \%$ (evident impairment). Following Jansiewicz et al ${ }^{39}$ children with ASD often also meet the criteria of DSM-IV for functional motor impairments. ${ }^{12,40}$ Generally, children with ASD show poorer performance in gross and fine MSs, 
motor flexibility, and balance. ${ }^{41-44}$ Further, Freitag et $\mathrm{al}^{42}$ found an association between lower static and dynamic balance and higher social withdrawal in children with ASD, while Rosenthal-Malek and Mitchell ${ }^{44}$ and Elliott et $\mathrm{al}^{45}$ found that regular PA reduced the occurrence of restricted and stereotypical pattern of behavior. Teitelbaum et $\mathrm{al}^{46}$ analyzed the motor behavior of 4- to 6-month-old infants and observed that peculiarities in motor behavior at this age such as the shape of the mouth and delays in some or all developmental milestones, including lying down, righting, sitting, crawling, and walking, predicted the emergence of ASD at the age of 3 years. Teitelbaum et $\mathrm{al}^{46}$ concluded that movement disturbances seemed to be important aspects of the phenomenon of autism even at a stage when ASD has not yet been diagnosed. We note that, following Teitelbaum et $\mathrm{al}^{46}$ movement disturbances are already observable during infancy and that, for example, following Rosenthal-Malek and Mitchell ${ }^{44}$ and Elliott et $\mathrm{l}^{45}$ regular PA might favorably impact on restricted and stereotypical behavior. Further, Lang et $\mathrm{al}^{47}$ speculated that poorer MS performance might also be due to more limited exercise opportunities and exercise activities. In this connection, Reid ${ }^{48}$ speculated that the lack of desire to participate in social activities such as ball games or leisure activities could also lead to reduced exercise activities and opportunities as compared to typically developing children. Lang et $\mathrm{al}^{47}$ summarized the results of 18 studies focusing on PA in individuals with ASD and concluded that regular PA impacted positively on stereotypical behaviors, aggression, self-harm, aberrant behavior during school classes, and school performance. In a further meta-analysis of 16 studies of PA in individuals with ASD, Sowa and Meulenbroek ${ }^{49}$ showed that individually tailored PA programs improved MSs and behavior, as compared to standardized group programs. We took these results into account and introduced a standardized, though individually performed, intervention program consisting of AET and MST. To take into account children's individual skills, the training programs were individually tailored to each participant.

In conclusion, we note that children with ASD suffer from poor sleep, and poor MSs, as compared to typically developing children. However, research also shows that PA has the potential to improve sleep, and almost by definition, MSs, though surprisingly, there is little research on these topics among children with ASD. We took these observations into account in devising a pilot exploratory study of the extent to which an AET and MST intervention might lead to positive changes in sleep and MSs among a small sample of children with ASD. We believe that the results may be of practical importance, given the following: a) prevalence rates of ASD are increasing, thus leading to higher demands for assistance and educational support; b) poor sleep and poor MSs are the most prominent impairments seen in ASD besides the core symptoms; c) PA is an attractive and low-cost intervention; d) any kind of improvement in the behavior and sleep of children with ASD has benefits on the psychological functioning of their close caregivers, ${ }^{25,50,51}$ and e) the sleep patterns of family members are intertwined. ${ }^{52,53}$ Accordingly, improved sleep in children with ASD should also improve the sleep of their close caregivers.

The following hypotheses were formulated. First, following Dworak et $\mathrm{al}^{32}$, Wachob and Lorenzi ${ }^{37}$, and Brand et $\mathrm{al}^{33}$ we expected more favorable objective sleep parameters such as extended deep sleep (DS), shorter sleep onset latency (SOL), and fewer awakenings after sleep onset following PA, as compared to sleep without preceding PA. Second, following Kalak et al, ${ }^{31}$ Lang et al, ${ }^{30}$ and Gerber et $\mathrm{al}^{37}$ we expected improvements in sleep (eg, more DS, less light sleep, fewer awakenings after sleep onset) as objectively assessed after the intervention compared to sleep before the intervention. Third, following Lang et $\mathrm{al}^{47}$ and Sowa and Meulenbroek ${ }^{49}$ we expected that MSs (eg, ball playing, balancing) would improve following the intervention. Fourth, following Kalak et $\mathrm{al}^{31}$ we anticipated improved mood and daytime functioning in children with ASD after PA intervention, as reported by parents.

\section{Methods \\ Sample}

Children with ASD were recruited from schools and centers in the central part of German-speaking Switzerland (Kanton Berne, Switzerland). Recruitment of the participants for this study was made via requests from various institutions that are active in the field of autism in Switzerland. The inclusion criterion was clinical diagnosis of an ASD, as carried out by experienced psychiatrists and psychologists. Further, a medical doctor, the parents, and the child decided together whether the child was able to participate with the required frequency in the training program. After parents signed the written informed consent, a trained psychologist not otherwise involved in the study performed a psychiatric diagnosis based on the Autism Diagnostic Observation Schedule ${ }^{54}$ and the revised Autism Diagnostic Interview. ${ }^{55}$ Mean age was 10 years (standard deviation [SD] =2.34; age range: 7-13 years; females: $50 \%$ ). Diagnosis was based on the ICD-10. ${ }^{56}$ Six out of ten participants suffered from infantile autism, three suffered from Asperger syndrome, and one child suffered from high-functioning autism. Further, a medical doctor not otherwise involved in the study performed a brief medical check to ensure that there were no medical risks in participating in 
the AET and MST. Given that the structure of the autistic symptoms lacked homogeneity across participants, a specific and individualized intervention was necessary. The Review Board of the University of Basel (Switzerland) approved the study, and the entire study was performed in accordance with the principles laid down in the Declaration of Helsinki.

\section{Intervention}

At the beginning of the intervention, for each child, an individual training plan was created. A training frequency of three sessions per week was planned with the intervention as a whole lasting 3 weeks. Each training session consisted of a 30-minute bicycle workout (AET) followed by 30 minutes of training in coordination and especially in balance (MST). The choice of a bicycle workout was made for the following reasons. Cycle training is easily adapted to individual motor abilities and allows specific progressive steps. In addition, it allows training in the endurance zone. According to Youngstedt et $\mathrm{al}^{57}$ endurance training in particular may have a positive influence on sleep. Additionally, the ability to cycle is an important capacity in everyday life and allows participation in social activities. Explicit facilitation of coordination ability (concrete balance and ball skills) has a scientific basis. Limitations have been reported for autistic children in gross and fine MSs as well as problems with balance. ${ }^{42,58}$ Likewise, in some studies, children with an ASD have displayed reduced ball skills. ${ }^{38}$ The intervention was executed in a highly structured manner and was based on the "Applied Behavioral Analysis" (ABA) method. ABA is based on the principles of operant conditioning with positive reinforcement as the principal feature. Children were positively reinforced verbally with compliments for every successful trial (playing with ball; balancing) and every effort on the bicycle. Further, daily and weekly improvements in skills were visualized with graphs and scales at home in the child's bedroom. Further, the training was adjusted according to the characteristics of autism present in each participant and was aimed at the important concept of errorless learning. Accordingly, the aims of MST were as follows: throwing a ball with one and two hands to the coach over a distance of 3-5 m (measurement: number of trials without interruption, that is, without losing the ball) and balancing (standing on one leg, jumping, jumping zigzag, balancing) on the beam (moderate-to-large sizes) without interruptions for at least 30 seconds (measurement: balancing time in seconds). Specific skills were assessed at the beginning and at the end of the intervention. Trials were repeated three times, and the best trial was used as baseline and as end point of the intervention.

\section{Tools}

Sleep

Objective sleep

The sleep-EEG device was applied four times: at the beginning and at the end of the study (nights not following PA), and two nights during the 2nd week following PA. Participants were requested to adhere to their normal evening routines, to go to bed at the usual time which was between $8 \mathrm{pm}$ and $9 \mathrm{pm}$ and to get up between 6 am and $7.30 \mathrm{am}$. Sleep-EEG recordings were performed at home using a one-channel EEG device (Fp2-A1; electro-oculogram; electromyogram; Somnowatch ${ }^{\circledR}$; Randersacker, Germany). Sleep polygraphs were visually analyzed by two experienced raters according to the standard procedures. ${ }^{59}$ Sleep parameters were analyzed according to the definitions in the standard program described by Lauer et al. ${ }^{60}$ The device was applied at about $7.30 \mathrm{pm}$ by a lab technician. The device provides assessment of total sleep time, sleep period time, SOL, sleep efficiency (SE), stages 1-4, light sleep (stages 1 and 2), slow wave sleep (SWS; stages 3 and 4), rapid eye movement sleep, rapid eye movement sleep latency, and number and time of awakenings after sleep onset.

Four sleep-EEG measurements were made: one at the beginning and one at the end of the study together with one on a night following PA training and one on a night that did not follow PA. To determine whether sleep improved over the course of the study, sleep-EEGs on the first night were compared with sleep-EEGs on the last night. To determine whether acute bouts of exercising influenced sleep, sleepEEGs with and sleep-EEGs without PA during the preceding day were compared.

\section{Subjective sleep}

Parents completed the Insomnia Severity Index (ISI), ${ }^{61} \mathrm{a}$ screening tool for insomnia. The seven items, answered on 5 -point rating scales $(1=$ not at all, $5=$ very much), refer to difficulty in falling asleep, difficulties maintaining sleep, increased daytime fatigue, and worrying about sleep. The higher the overall score, the more the respondent is assumed to suffer from insomnia (Cronbach's alpha $=0.89$ ). Additionally, the following cut-off criteria ${ }^{61}$ were applied: $0-7$ points: no clinically significant insomnia; $8-14$ points: subthreshold insomnia; 15-21 points: clinical insomnia (moderate severity); and 22-28 points: clinical insomnia (severe).

\section{Sleep schedules and sleep-related psychological functioning}

To assess sleep schedules and sleep-related psychological functioning, we administered a brief questionnaire based 
on the Pittsburgh Sleep Quality Index. ${ }^{62}$ Parents were asked about sleep duration (hours), SOL (minutes), and number of awakenings after sleep onset for the last 5 working days. Additionally, parents reported, on 8-point Likert-scales, for the mornings: sleep quality ( $1=$ very good sleep quality), feeling of being restored ( $1=$ completely restored $)$, and mood in the morning ( $1=$ very good mood). The log was completed the 1 st and the $3 \mathrm{rd}$ week, and data were aggregated to form composite variables for the 1 st week and for the $3 \mathrm{rd}$ week (Cronbach's alpha $=0.84$ ).

\section{Statistical analysis}

An odds ratio was calculated to estimate the odds of suffering from insomnia in the present sample of children with ASD as compared to typically developing children. To compare subjective sleep quality over time, a $t$-test for paired samples was performed. To compare objective sleep measures over time, a series of $t$-tests for paired samples was performed. A series of $t$-tests for paired samples was also performed to compare the sleep and mood log data between the 1st and the 3 rd week, as well as the dimensions of MSs. To compare objective sleep parameters between nights following PA and nights without preceding PA, as a first step, the two measurements of nights following PA and the two nights not following PA were separately aggregated to single nights with or without preceding PA. This was followed by a series of $t$-tests for paired samples.

Test results with an alpha level of below 0.05 were reported as significant. However, we placed particular emphasis on effect sizes, which take into account mean differences and SDs without being sensitive to sample sizes. For $t$-tests, these were calculated following Cohen ${ }^{63}$ with $0.20<d>0.49$ indicating small (ie, negligible practical importance), $0.50<d<0.79$ indicating medium (ie, moderate practical importance), and $d>0.80$ indicating large (ie, crucial practical importance) effect sizes. All statistics were processed using SPSS ${ }^{\circledR} 20.0$ (IBM Corporation, Armonk, NY, USA) for Apple McIntosh ${ }^{\circledR}$.

\section{Results}

All children participated in all assessments, activities, and sleep measurements.

\section{Subjective sleep over time (ISI scores)}

Subjective sleep scores did not change over time (baseline: mean $=11.60, \mathrm{SD}=6.02$; end of the study: mean $=10.81$, $\mathrm{SD}=6.76 ; t(9)=0.63, P=0.55)$. Seven out of ten children were categorized as suffering from subthreshold to clinically relevant insomnia. Compared to normative data (insomnia scores: $20 \%-25 \%),{ }^{26}$ the odds of suffering from insomnia were $9.33-$ fold higher in children with ASD than in typically developing children (odds ratio $=9.33$, confidence interval $=1.19-72.99$ )

\section{Objective sleep over time}

Table 1 gives the descriptive and statistical objective sleep parameters at the beginning and at the end of the study. No significant changes were observed.

\section{Objective sleep on nights with previous PA and nights without previous PA}

Table 2 gives the descriptive and statistical objective sleep parameters for nights preceded by PA and nights without preceding PA. Relative to nights without preceding PA, on nights following PA, SE increased, relative DS or SWS increased, and awakening times after sleep onset and SOL decreased (all effect sizes were medium to large). No differences were observed for total sleep time, number of awakenings after sleep onset, or light sleep.

Table I Descriptive and statistical overview of objective sleep variables at baseline and at the end of the study 3 weeks later

\begin{tabular}{|c|c|c|c|c|c|}
\hline & \multicolumn{4}{|c|}{ Time points } & \multirow[t]{3}{*}{ Effect sizes } \\
\hline & \multicolumn{2}{|c|}{ Baseline } & \multicolumn{2}{|c|}{ End of the study } & \\
\hline & Mean & SD & Mean & SD & \\
\hline TST (hour:minutes) & $7: 55$ & $46: 52$ & $7: 49$ & $53: 10$ & $0.15[S]$ \\
\hline Sleep efficiency (\%) & 93.03 & 4.57 & 96.76 & 1.801 & $0.13[S]$ \\
\hline Sleep onset latency (minutes:seconds) & $15: 20$ & $|4: 2|$ & $18: 12$ & $14: 43$ & $0.09[\mathrm{~S}]$ \\
\hline Number of awakenings after sleep onset & 5.56 & 2.03 & 5.35 & 4.34 & $0.17[S]$ \\
\hline Time awake after sleep onset (minutes:seconds) & $27: 37$ & $19: 19$ & $17: 87$ & $15: 34$ & $0.19[S]$ \\
\hline Time light sleep (hour:minutes) & $3: 24$ & $0: 23$ & $3: 26$ & $\mathrm{I}: 04$ & $0.09[\mathrm{~S}]$ \\
\hline Light sleep (\%) & 43.00 & 7.34 & 42.68 & 16.46 & $0.14[S]$ \\
\hline Time deep sleep (hour:minutes) & $2: 21$ & $0: 42$ & $2: 47$ & $0: 56$ & $0.21[S]$ \\
\hline Deep sleep $(\%)$ & 29.34 & 7.86 & 31.45 & 8.67 & $0.21[S]$ \\
\hline REM sleep (hour:minutes) & $\mathrm{I}: 27$ & $0: 35$ & $\mathrm{I}: \mathrm{II}$ & $0: 33$ & $0.47[\mathrm{~S}]$ \\
\hline REM sleep (\%) & 18.32 & 4.24 & 14.93 & 5.14 & $0.72[\mathrm{M}]$ \\
\hline
\end{tabular}

Abbreviations: SD, standard deviation; TST, total sleep time; REM, rapid eye movement; S, small; M, medium. 
Table 2 Comparisons of objective sleep data from nights following physical activity and nights not following physical activity

\begin{tabular}{|c|c|c|c|c|c|}
\hline & \multicolumn{4}{|c|}{ Intervention } & \multirow[t]{3}{*}{ Effect sizes } \\
\hline & \multicolumn{2}{|c|}{ Without previous PA } & \multicolumn{2}{|c|}{ With previous PA } & \\
\hline & Mean & SD & Mean & SD & \\
\hline TST (hours:minutes) & $7: 45$ & $\mathrm{I}: 03$ & $7: 35$ & $1: 53$ & $0.11[S]$ \\
\hline Sleep efficiency (\%) & 93.03 & 4.570 & 96.76 & $\mathrm{I} .80$ & $\mathrm{I} .07[\mathrm{~L}]$ \\
\hline Sleep onset latency (minutes:seconds) & $13: 20$ & $15: 27$ & 09:24 & $6: 37$ & $0.38[S]$ \\
\hline Number of awakenings after sleep onset & 6.00 & 1.528 & 3.67 & 2.94 & $0.39[\mathrm{~S}]$ \\
\hline Time awake after sleep onset (minutes:seconds) & $30: 37$ & $22: 11$ & $\mathrm{II}: 46$ & $11: 26$ & $\mathrm{I} .09$ [L] \\
\hline Time light sleep (hours:minutes) & $3: 31$ & $0: 29$ & $3: 26$ & $\mathrm{I}: 4 \mathrm{I}$ & $0.07[S]$ \\
\hline Light sleep (\%) & 45.80 & 5.43 & 43.60 & 14.47 & $0.20[\mathrm{~S}]$ \\
\hline Time deep sleep (hours:minutes) & $2: 32$ & $0: 42$ & $2: 41$ & $0: 25$ & $0.26[S]$ \\
\hline Deep sleep (\%) & 32.80 & 7.67 & 36.63 & 8.27 & $0.51[\mathrm{M}]$ \\
\hline REM sleep (hours:minutes) & $0: 55$ & $0: 34$ & $\mathrm{I}: 06$ & $0: 45$ & $0.28[\mathrm{~S}]$ \\
\hline REM sleep (\%) & 11.83 & 4.68 & 14.05 & 5.68 & $0.42[S]$ \\
\hline
\end{tabular}

Abbreviations: PA, physical activity; SD, standard deviation; TST, total sleep time; REM, rapid eye movement; S, small; M, medium; L, large.

\section{Sleep and mood, as assessed via sleep logs}

Table 3 gives the descriptive aggregated values from week 1 and week 3 and the comparison between these 2 weeks. Subjective sleep quality and mood in the morning improved over time (moderate-to-large effect sizes). No meaningful effect sizes were observed on any other dimensions.

\section{Motor skills}

Table 4 gives the descriptive and statistical MS performance at the beginning and at the end of the intervention. Improvements were observed for catching, throwing a ball with one and two hands, and balancing (standing on one leg, jumping, jumping zigzag, balancing) on the beam (moderate-to-large sizes).

\section{Discussion}

The key findings of the present study are that in a small sample of children with ASD, a 3-week intervention involving AET and MST improved specific MSs and led to improved objectively assessed sleep on nights following PA as compared to nights not preceded by PA. Mood also improved over time.

Four hypotheses were formulated, and each is now considered in turn.

Our first hypothesis was that favorable objective sleep parameters would be more positive following PA, as compared to sleep without prior PA, and this hypothesis was supported. Accordingly, the present findings confirm those of previous research, ${ }^{36,37}$ though in our view, they also expand upon previous findings because we were able to show this association among children with ASD. Thus, for children with ASD, physical activities in the form of both
AET and MST during the day are able to improve specific sleep parameters such as SE $(d=1.07)$, wake time after sleep onset $(d=1.09)$, and SOL $(d=0.38)$. It is also worth noting that the amount of SWS increased $(d=0.48)$, given that on

Table 3 Descriptive and statistical overview of the sleep and mood values in the morning, as reported in the logs and as rated by parents

\begin{tabular}{|c|c|c|c|c|c|}
\hline & Mean & SD & $t$-value & Significance & ES \\
\hline \multicolumn{6}{|c|}{ Sleep quality ( $\mathrm{I}=$ excellent, $8=$ very poor $)$} \\
\hline Week I & 3.60 & 1.78 & \multirow[t]{2}{*}{1.11} & \multirow[t]{2}{*}{0.29} & \multirow[t]{2}{*}{0.51} \\
\hline Week 3 & 2.88 & 1.11 & & & \\
\hline \multicolumn{6}{|c|}{ Seeming to be restored ( $\mathrm{I}=$ absolutely restored, $8=$ not at all restored) } \\
\hline Week I & 3.95 & 1.57 & \multirow[t]{2}{*}{0.74} & \multirow{2}{*}{0.913} & \multirow[t]{2}{*}{0.05} \\
\hline Week 3 & 3.40 & 1.33 & & & \\
\hline \multicolumn{6}{|c|}{ Mood morning ( $I=$ excellent, $8=$ very poor) } \\
\hline Week I & 3.85 & 1.00 & \multirow[t]{2}{*}{1.87} & \multirow[t]{2}{*}{0.094} & \multirow[t]{2}{*}{0.90} \\
\hline Week 3 & 2.90 & 1.10 & & & \\
\hline \multicolumn{6}{|c|}{ Tiredness evening $(\mathrm{I}=$ not at all, $8=$ extreme tiredness $)$} \\
\hline Week I & 5.52 & 1.76 & \multirow[t]{2}{*}{-0.465} & \multirow[t]{2}{*}{0.653} & \multirow[t]{2}{*}{0.08} \\
\hline Week 3 & 5.66 & 1.53 & & & \\
\hline \multicolumn{6}{|c|}{ Light switched off (hour:minutes) } \\
\hline Week I & $21: 04$ & $\mathrm{I}: 1 \mathrm{I}$ & \multirow[t]{2}{*}{-0.324} & \multirow[t]{2}{*}{0.753} & \multirow[t]{2}{*}{0.05} \\
\hline Week 3 & $21: 08$ & $1: 17$ & & & \\
\hline \multicolumn{6}{|c|}{ Sleep onset latency (hour:minutes) } \\
\hline Week I & $0: 29$ & $0: 14$ & \multirow[t]{2}{*}{-0.803} & \multirow[t]{2}{*}{0.443} & \multirow[t]{2}{*}{0.39} \\
\hline Week 3 & $0: 37$ & $0: 21$ & & & \\
\hline \multicolumn{6}{|c|}{ Number of awakenings after sleep onset } \\
\hline Week I & 1.07 & 1.13 & \multirow[t]{2}{*}{-1.21} & \multirow[t]{2}{*}{0.395} & \multirow[t]{2}{*}{0.32} \\
\hline Week 3 & 1.30 & 1.40 & & & \\
\hline \multicolumn{6}{|c|}{ Duration of awakenings (hour:minutes) } \\
\hline Week I & $0: 05$ & 0:06 & \multirow[t]{2}{*}{-1.133} & \multirow[t]{2}{*}{0.286} & 0.36 \\
\hline Week 3 & $0: 08$ & $0: 10$ & & & \\
\hline Wake time & ur:minu & & & & \\
\hline Week I & $6: 48$ & $1: 00$ & 0.379 & 0.714 & 0.10 \\
\hline Week 3 & $6: 42$ & I:04 & & & \\
\hline TST (hour:r & utes) & & & & \\
\hline Week I & $9: 07$ & $0: 26$ & 1.615 & 0.141 & 0.32 \\
\hline Week 3 & $8: 46$ & $0: 51$ & & & \\
\hline
\end{tabular}

Abbreviations: SD, standard deviation; ES, effect size; TST, total sleep time. 
Table 4 Descriptive and statistical overview of motor skill performance at the beginning and at the end of the intervention $(\mathrm{N}=10)$

\begin{tabular}{|c|c|c|c|c|}
\hline & Mean & SD & $t$-value & Significance \\
\hline \multicolumn{5}{|l|}{ Balla } \\
\hline \multicolumn{5}{|l|}{ Catching } \\
\hline Baseline & 10.40 & 3.52 & & \\
\hline End & 14.32 & 3.45 & & \\
\hline \multicolumn{5}{|l|}{ Throwing } \\
\hline Baseline & 7.41 & 4.54 & & \\
\hline End & 9.30 & 2.46 & & \\
\hline \multicolumn{5}{|c|}{ Sum ball skills } \\
\hline Baseline & 8.9 & 5.47 & -4.302 & 0.002 \\
\hline End & 11.8 & 4.71 & & \\
\hline \multicolumn{5}{|c|}{ Balancing one leg; large beam } \\
\hline Baseline & 21.89 & 4.85 & & \\
\hline End & 29.93 & 3.99 & & \\
\hline \multicolumn{5}{|c|}{ Balancing two legs; moderate beam } \\
\hline Baseline & 33.78 & 6.45 & & \\
\hline End & 40.78 & 5.45 & & \\
\hline \multicolumn{5}{|c|}{ Sum balancing ${ }^{\mathrm{b}}$} \\
\hline Baseline & 27.40 & 5.82 & 3.030 & 0.014 \\
\hline End & 35.40 & 5.71 & & \\
\hline
\end{tabular}

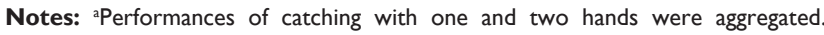
'Performance of balancing with one and two legs on the moderate and large beam. Abbreviation: SD, standard deviation.

a behavioral level, these sleep indices are among the most irritating issues for both the children affected and their close caregivers. Indeed, low SE, long sleep onset latencies, and frequent awakenings after sleep onset are often observed in children with ASD, ${ }^{17,18,25}$ and it seems that both AET and MST counteract these difficulties. However, the present data do not provide any insight into underlying psychophysiological mechanisms. Whereas Lang et $\mathrm{al}^{47}$ for example, argued that physical fatigue is the key factor leading to increased sleep after PA in children with ASD, there are at least three other possibilities. First, we note that SWS increased, and Dworak et $\mathrm{al}^{32}$ have speculated that the amount of SWS is homeostasis-regulated and directly linked to brain energy metabolism. Accordingly, it is conceivable that SWS is necessary for replenishment, since brain energy metabolism decreases dramatically during SWS. ${ }^{64,65}$ Second, it is conceivable that increased PA may have improved SWS via an increase in growth hormone (GH) secretion. ${ }^{66,67}$ Third, we also observed that the wake time after sleep onset decreased by $63 \%(d=1.09)$, and we know that, for instance, both increased secretion of GH and adenosine and reduced secretion of cortisol are associated with less interrupted sleep continuity. ${ }^{67}$ Whereas the present data did not allow us to test these possibilities, future studies should therefore assess neuro-endocrinological processes during sleep in children with ASD.
Our second hypothesis was that objective sleep would increase following the intervention, but this was not supported, a finding at odds with previous research. ${ }^{31}$ Accordingly, there is reason to suppose that the intervention may not have been of sufficient duration, frequency, or intensity to influence sleep regulation, and ultimately, brain activity in the longer term. However, we note that in the present study, children's subjective sleep was rated by their parents, which further adds to the difficultly of comparisons with other studies.

Our third hypothesis was that MSs would improve following the intervention, and this hypothesis was fully confirmed; children improved in areas related to fine MSs such as catching a ball and throwing a ball with one or with two hands ( $d s=0.57-2.40)$. Likewise, fine MSs in balancing (standing on one leg, forward, jumping zigzag, balancing on a beam) improved dramatically $(d s=0.51-5.66)$. Accordingly, the present pattern of results fits well with previous research. ${ }^{47,49}$ However, these results differ from and add to previous research because these improvements were observed within the relatively short time lapse of 3 weeks, or after just nine sessions, and in which both skill training and endurance performance were trained. Thus, improvements appeared quite rapidly. There is a broad agreement that in children with ASD, physical and leisure time activities are reduced relative to typically developing children, which in turn will affect learning and opportunities for learning. ${ }^{68-70}$ For example, MacDonald et $\mathrm{al}^{13}$ recorded an average for moderate-to-strenuous PA of 17 minutes per day after school for children with ASD, and an average of 10 minutes per day after school for adolescents with ASD. MacDonald et a ${ }^{13}$ did not compare these averages with evidence from typically developing children, though other studies ${ }^{71}$ have reported substantially higher rates of moderate-to-vigorous PA in typically developing children and adolescents. MacDonald et $\mathrm{al}^{13}$ noted in addition that $43 \%$ of their ASD participants were overweight. Being overweight during childhood and adolescence is associated with increased risk of cardiovascular and psychological issues during adulthood, ${ }^{72}$ thus justifying any additional effort to promote PA among children with ASD. In this regard, Pitetti et a ${ }^{73}$ showed that a walking program lasting 9 months both increased physical strength and reduced body mass index in ten adolescents with ASD, relative to a control condition.

Overall, our findings suggest that specific MST can be successful in terms of specific improvements. However, a limitation of the present study is that it remained unclear as to what extent these improvements produced reductions in 
stereotypical pattern of behavior and interests. Future studies might therefore assess possible changes in these aspects of ASD following PA interventions. We were unable to replicate the findings of Rosenthal-Malek and Mitchell ${ }^{44}$ and Elliott et $\mathrm{al}^{45}$ that regular PA reduced restricted and stereotypical pattern of behavior.

Our fourth and last hypothesis was that mood and daytime functioning would improve following a PA intervention. This hypothesis was only partially confirmed, in that mood in the morning improved but there were no changes in any of the other psychological characteristics assessed. The following are possible reasons for the lack of significant differences: (a) the time interval of 3 weeks was too short to produce the relevant changes; (b) logs were completed by parents and thus did not involve self-perceptions; and (c) there may have been changes over time on other psychological dimensions but too subtle to be captured by the questionnaires used. On the other hand, we note that also among healthy adolescents, not all dimensions of psychological functioning changed following a PA intervention lasting 3 weeks; whereas mood and pain perception improved, perceived stress and coping strategies did not, ${ }^{31}$ suggesting therefore that positive changes should not necessarily be expected on all dimensions. In our opinion, this observation does help to make some sense of the lack of significant differences found in the present study.

Despite the new findings, several limitations warrant against overgeneralization of the present results. First, the sample size is small, and statistical power is low, though we relied on effect size calculations, which take into account mean differences and SDs without being sensitive to sample sizes. Second, the study design involved a within-group- and pre-post-comparison; future studies might also add control groups such as children with ASD on a waiting list and healthy controls. Third, there was no longer term follow-up; future studies might also prolong the intervention, evaluate the ecological validity of the intervention, and investigate to what extent the intervention had an impact, for example, on the family system as studies show that burden is higher for mothers of children with ASD than it is for mothers of children with other mental disorders. ${ }^{25}$ Fourth, all questionnaires were completed by parents (usually mothers); self-reported data would have been useful, though there is agreement that the self-reports and compliance of children with ASD are not always reliable. Future studies should try to assess self-reports and reports from others such as teachers and health care providers. Fifth, with regard to the assessment of children's sleep, we became aware only after completion of the study that the Children's Sleep Habits Questionnaire (CSHQ) ${ }^{74}$ would have been a better option because the CSHQ assesses not only sleep quality, as we did with the ISI, but also information about sleep structures (bed time, awakenings, etc) and also respiration and parasomnias (night walking, night terrors, etc). This holds particularly true because breathing-related issues are often observed among children with ASD ${ }^{75}$ Sixth, the study design does not allow us to say whether the favorable effects are due to the AET, the MST, or their combination. Seventh, we are aware that the variety of MSs is not limited to biking, ball playing, and balancing, though, given that children with ASD suffer from a broad variety of impaired $\mathrm{MSs},{ }^{76}$ we hold that biking and ball playing provide a good start toward increased and ultimately socially more involving activities. Last, half of the participants were female; this ratio is at odds with epidemiologic data showing sex ratios of 3-4:1 in favor of males. Accordingly, the present sample is unrepresentative as regards sex distribution.

\section{Conclusion}

Among a small sample of children with ASD, regular AET and MST delivered over a period of 3 weeks improved objective sleep on nights immediately following the training and improved MSs.

\section{Acknowledgment}

We thank Nick Emler (University of Surrey, UK) for proofreading the paper.

\section{Disclosure}

The authors report no conflicts of interest in this work.

\section{References}

1. Khan NZ, Gallo LA, Arghir A, et al. Autism and the grand challenges in global mental health. Autism Res. 2012;5(3):156-159.

2. American Psychiatric Association. Diagnostic and Statistical Manual of Mental Disorders (DSM 5). 5th ed. Washington, DC: American Psychiatric Association; 2013.

3. Wisconsin. 2015. Available from: http://www.sped.dpi.wi.gov/sped_ ccreports. Accessed January 14, 2015.

4. Baxter AJ, Brugha TS, Erskine HE, Scheurer RW, Vos T, Scott JG. The epidemiology and global burden of autism spectrum disorders. Psychol Med. 2014;11:1-13.

5. Croen LA, Najjar DV, Ray GT, Lotspeich L, Bernal P. A comparison of health care utilization and costs of children with and without autism spectrum disorders in a large group-model health plan. Pediatrics. 2006; 118(4):e1203-e1211.

6. Feinberg E, Augustyn M, Fitzgerald E, et al. Improving maternal mental health after a child's diagnosis of autism spectrum disorder: results from a randomized clinical trial. JAMA Pediatr. 2014;168(1):40-46.

7. Liu X, Hubbard JA, Fabes RA, Adam JB. Sleep disturbances and correlates of children with autism spectrum disorders. Child Psychiatry Hum Dev. 2006;37:179-191. 
8. Richdale AL, Schreck KA. Sleep problems in autism spectrum disorders: prevalence, nature and possible biopsychosocial aetiologies. Sleep Med Rev. 2009;13:403-411.

9. Ming X, Brimacombe M, Chaaban J, Zimmerman-Bier B, Wagner GC. Autism spectrum disorders: concurrent clinical disorders. J Child Neurol. 2008;23(1):6-13.

10. Paavonen EJ, Vehkalahti K, Vanhala R, Von Wendt L, Nieminen-von Wendt T, Aronen ET. Sleep in children with Asperger syndrome. J Autism Dev Dis. 2008;38:41-51.

11. Green D, Charman T, Pickles A, et al. Impairment in movement skills of children with autistic spectrum disorders. Dev Med Child Neurol. 2009;51:311-316.

12. Fournier KA, Hass CJ, Naik SK, Lodha N, Cauraugh JH. Motor coordination in autism spectrum disorders: a synthesis and meta-analysis. J Autism Dev Dis. 2010;40:1227-1240.

13. MacDonald M, Esposito P, Ulrich D. The physical activity patterns of children with autism. BMC Res Notes. 2011;4:422-426.

14. Gregory AM, Sadeh A. Sleep, emotional and behavioral difficulties in children and adolescents. Sleep Med Rev. 2012;16(2):129-136.

15. Lemola S, Räikkönen K, Scheier MF, et al. Sleep quantity, quality and optimism in children. J Sleep Res. 2011;20:12-20.

16. Kalak N, Lemola S, Brand S, Holsboer-Trachsler E, Grob A. Sleep duration and subjective psychological well-being in adolescence: a longitudinal study in Switzerland and Norway. Neuropsychiatr Dis Treat. 2014;10:1199-1207.

17. Souders MC, Mason TB, Valladares O, et al. Sleep behaviors and sleep quality in children with autism spectrum disorders. Sleep. 2009; 32(12):1566-1578.

18. Sikora DM, Johnson K, Clemons T, Katz T. The relationship between sleep problems and daytime behavior in children of different ages with autism spectrum disorders. Pediatrics. 2012;130(suppl 2):S83-S90.

19. Mindell JA, Emslie G, Blumer J, et al. Pharmacologic management of insomnia in children and adolescents: consensus statement. Pediatrics. 2006;117:e1223-e1232.

20. Hare DJ, Jones S, Evershed K, Hare DJ, Jones S, Evershed K. Objective investigation of the sleep-wake cycle in adults with intellectual disabilities and autistic spectrum disorders. J Intellect Disabil Res. 2006; 50:701-710.

21. Cortesi F, Giannotti F, Ivanenko A, Johnson K. Sleep in children with autistic spectrum disorder. Sleep Med. 2010;11:659-664.

22. Couturier JL, Speechley KN, Steele M, Norman R, Stringer B, Nicolson R. Parental perception of sleep problems in children of normal intelligence with pervasive developmental disorders: prevalence, severity, and pattern. J Am Acad Child Adolesc Psychiatry. 2005;44:815-822.

23. Schreck KA, Mulick JA, Smith AF. Sleep problems as possible predictors of intensified symptoms of autism. Res Dev Disabil. 2004;25: 57-66.

24. Malow BA, Marzec ML, McGrew SG, Wang L, Henderson LM, Stone WL. Characterizing sleep in children with autism spectrum disorders: a multidimensional approach. Sleep. 2006;29(12):1563-1571.

25. Wiggs L, Stores G. Sleep patterns and sleep disorders in children with autistic spectrum disorders: insights using parent report and actigraphy. Dev Med Child Neurol. 2004;46:372-380.

26. Hatzinger M, Brand S, Perren S, et al. In pre-school children, sleep objectively assessed via sleep-EEGs remains stable over 12 months and is related to psychological functioning, but not to cortisol secretion. J Psychiatr Res. 2013;47:1809-1814.

27. Brand S, Hatzinger M, Stadler C, et al. Does objectively assessed sleep at five years predict sleep and psychological functioning at 14 years? Hmm, yes and no! J Psychiatr Res. 2015;60:148-155.

28. Brand S, Gerber M, Beck J, Hatzinger M, Pühse U, Holsboer-Trachsler E. Exercising, sleep-EEG patterns, and psychological functioning are related among adolescents. World J Biol Psychiatry. 2010;11:129-140.

29. Brand S, Beck J, Gerber M, Hatzinger M, Holsboer-Trachsler E. Evidence of favorable sleep-EEG patterns in adolescent male vigorous football players compared to controls. World J Biol Psychiatry. 2010;11: 465-475.
30. Lang C, Brand S, Feldmeth AK, Holsboer-Trachsler E, Pühse U, Gerber M Increased self-reported and objectively assessed physical activity predict sleep quality among adolescents. Physiol Behav. 2013;120: 46-53

31. Kalak N, Gerber M, Kirov R, et al. Thirty minutes of daily morning running for three weeks improved sleep and psychological functioning in healthy adolescents compared to controls. J Adolesc Health. 2012;51: 615-622.

32. Dworak M, Wiater A, Alfer D, Stephan E, Hollmann W, Strüder HK. Increased slow wave sleep and reduced stage 2 sleep in children depending on exercise intensity. Sleep Med. 2008;9(3):266-272.

33. Brand S, Kalak N, Gerber M, Kirov R, Pühse U, Holsboer-Trachsler E. High self-perceived exercise exertion before bedtime is associated with greater objectively assessed sleep efficiency. Sleep Med. 2014;15: 1031-1036.

34. Buman MP, Phillips BA, Youngstedt SD, Kline CE, Hirshkowitz M. Does nighttime exercise really disturb sleep? Results from the 2013 National Sleep Foundation Sleep in America Poll. Sleep Med. 2014;15: 755-761.

35. Loprinzi PD, Cardinal BJ. Association between objectively-measured physical activity and sleep, NHANES 2005-2006. Mental Health Phys Act. 2011;4:65-69.

36. Gerber M, Brand S, Herrmann C, Colledge F, Holsboer-Trachsler E, Pühse U. Increased objectively assessed vigorous-intensity exercise is associated with reduced stress, increased mental health and good objective and subjective sleep in young adults. Physiol Behav. 2014;135: 17-24.

37. Wachob D, Lorenzi DG. Brief report: Influence of physical activity on sleep quality in children with Autism. J Autism Dev Disord. 2015.

38. Hinckson EA, Dickinson A, Water T, Sands M, Penman L. Physical activity, dietary habits and overall health in overweight and obese children and youth with intellectual disability or autism. Res Dev Disabil. 2013;34:1170-1178.

39. Jansiewicz EM, Goldberg MC, Newschaffer CJ, Denckla MB, Landa R, Mostofsky SH. Motor signs distinguish children with high functioning autism and Asperger's syndrome from controls. J Autism Dev Disord. 2006;36:613-621

40. MacDonald M, Lord C, Ulrich DA. Motor skills and calibrated autism severity in young children with autism spectrum disorder. Adapt Phys Activ Q. 2014;31:95-105.

41. Dodd S. Autismus. Heidelberg: Spektrum Akadmischer Verlag; 2007.

42. Freitag CM. Autismus-Spektrum-Störungen. München: Ernst Reinhardt, $\mathrm{GmbH} \& \mathrm{Co} \mathrm{KG} ; 2008$.

43. Freitag CM, Kieser C, Schneider M, Von Gontard A. Quantitative assessment of neuromotor function in adolescents with high functioning autism and asperger syndrome. J Autism Dev Disord. 2007;37: 948-959.

44. Rosenthal-Malek A, Mitchell S. The effects of exercise on the selfstimulatory behaviors of adolescents with autism. J Autism Dev Disord. 1997;27(I):193-201.

45. Elliott RO, Dobbin AR, Rose GD, Soper HV. Vigorous, aerobic exercise versus general motor training activities: effects on maladaptive and stereotypic behaviors of adults with both autism and mental retardation. J Autism Dev Disord. 1994;24(5):565-576.

46. Teitelbaum P, Teitelbaum O, Nye J, Fryman J, Maurer RG. Movement analysis in infancy may be useful for early diagnosis of autism. Proc Natl Acad Sci U S A. 1998;95(23):13982-13987.

47. Lang R, Kern-Koegel L, Ashbaugh K, Regester A, Ence W, Smith W. "Physical exercise and individuals with autism spectrum disorders: a systematic review. Res Autism Spectr Disord. 2010;4:565-576.

48. Reid $\mathrm{G}$. Understanding physical activity in youths with autism spectrum disorders. Palaestra. 2005;21(4):6-7.

49. Sowa M, Meulenbroek R. Effects of physical exercise on autism spectrum disorders: a meta-analysis. Res Autism Spectr Disord. 2012;6:46-57.

50. Meltzer LJ. Brief report: sleep in parents of children with autism spectrum disorders. J Pediatr Psychol. 2008;33:380-386. 
51. Dykens EM, Fisher MH, Taylor JL, Lambert W, Miodrag N. Reducing distress in mothers of children with autism and other disabilities: a randomized trial. Pediatrics. 2014;134(2):e454-e463.

52. Kalak N, Gerber M, Kirov R, et al. The relation of objective sleep patterns, depressive symptoms, and sleep disturbances in adolescent children and their parents: a sleep-EEG study with 47 families. J Psychiatr Res. 2012;46:1374-1382.

53. Bajoghli H, Alipouri A, Holsboer-Trachsler E, Brand S. Sleep patterns and psychological functioning in families in northeastern Iran; evidence for similarities between adolescent children and their parents. J Adolesc. 2013;36:1103-1113.

54. Lord C, Rutter M, DiLavore P, Risi S. Autism Diagnostic Observation Schedule: Manual. Los Angeles: Western Psychological Services; 1999.

55. Rutter M, Le Couteur A, Lord C. Autism Diagnostic Interview-RevisedWPS. WPS ed. Los Angeles: Western Psychological Services; 2003.

56. WHO. 2015. Available from: http://www.who.int/classifications/icd/ en/. Accessed January 22, 2015.

57. Youngstedt SD, O'Connor PJ, Dishman RK. The effects of acute exercise on sleep: a quantitative synthesis. Sleep. 1997;20(3):203-214.

58. Landa R, Garrett-Mayer E. Development in infants with autism spectrum disorders: a prospective study. J Child Psychol Psychiatry. 2006; 47:629-638.

59. Rechtschaffen A, Kales A. A Manual for Standardized Terminology, Techniques and Scoring System for Sleep Stages of Human Subjects. Brain Information Service. Los Angeles: Brain Research Institute; 1968. NIH Publ. No. 204.

60. Lauer CJ, Riemann D, Wiegand M, Berger M. From early to late adulthood: changes in EEG sleep of depressed patients and healthy volunteers. Biol Psychiatry. 1991;29:979-993.

61. Bastien CH, Vallières A, Morin CM. Validation of the Insomnia Severity Index as an outcome measure for insomnia research. Sleep Med. 2001; 2:97-307.

62. Buysse DJ, Reynolds CF, Monk TH, Berman SR, Kupfer DJ. The Pittsburgh Sleep Quality Index: new instrument for psychiatric practice and research. Psychiatry Res. 1989;28:193-213.

63. Cohen J. Statistical Power Analysis for the Behavioural Sciences. 2nd ed. Hillsdale, NJ: Lawrence Erlbaum Associates; 1988.

64. Benington J, Heller H. Restoration of brain energy metabolism as the function of sleep. Prog Neurobiol. 1995;45:347-360.
65. Nofzinger EA, Buysse DJ, Miewald JM, et al. Human regional cerebral glucose metabolism during non-rapid eye movement sleep in relation to waking. Brain. 2000;125:1105-1115.

66. Wideman L, Weltman JY, Hartman ML, Veldhuis JD, Weltman A. Growth hormone release during acute and chronic aerobic and resistance exercise. Sports Med. 2002;32:987-1004.

67. Steiger A, Dresler M, Kluge M, Schüssler P. Pathology of sleep, hormones and depression. Pharmacopsychiatry. 2013;46(suppl 1): S30-S35.

68. Hilton CL, Crouch MC, Israel H. Out-of-school participation patterns in children with high-functioning autism spectrum disorders. Am J Occup Ther. 2008;62:554-563.

69. Hochhauser M, Engel-Yeger B. Sensory processing abilities and their relation to participation in leisure activities among children with high functioning autism spectrum disorder (HFASD). Res Autism Spectr Disord. 2010;4:746-754.

70. Potvin MC, Snider L, Prelock P, Kehayia E, Wood-Dauphinee S. Recreational participation of children with high functioning autism. J Autism Dev Disord. 2012;43:445-457.

71. Brand S, Gerber M, Kalak N, et al. Adolescents with greater mental toughness show higher sleep efficiency, more deep sleep and fewer awakenings after sleep onset. J Adolesc Health. 2014;54:109-113.

72. McMullen S. Childhood obesity: the impact on long-term risk of metabolic and CVD is not necessarily inevitable. Proc Nutr Soc. 2014; 73(3):389-396.

73. Pitetti KH, Rendoff AD, Grover T, Beets MW. The efficacy of a 9-month treadmill walking program on the exercise capacity and weight reduction for adolescents with severe autism. J Autism Dev Disord. 2007; 37:997-1006.

74. Owens JA, Spirito A, McGuinn M. The Children's Sleep Habits Questionnair (CSHQ): psychometric properties of a survey instrument for school-aged children. Sleep. 2000;23:1043-1051.

75. Hoffman CD, Sweeney DP, Gilliam JE, Apodaca DD, Lopez-Wagner MC, Castillo MM. Sleep problems and symptomatology in children with autism. Focus Autism Other Dev Disabil. 2005;20:194-200.

76. Gowen E, Hamilton A. Motor abilities in autism: a review using a computational context. J Autism Dev Disord. 2013;43:323-344.
Neuropsychiatric Disease and Treatment

\section{Publish your work in this journal}

Neuropsychiatric Disease and Treatment is an international, peerreviewed journal of clinical therapeutics and pharmacology focusing on concise rapid reporting of clinical or pre-clinical studies on a range of neuropsychiatric and neurological disorders. This journal is indexed on PubMed Central, the 'PsycINFO' database and CAS,

\section{Dovepress}

and is the official journal of The International Neuropsychiatric Association (INA). The manuscript management system is completely online and includes a very quick and fair peer-review system, which is all easy to use. Visit http://www.dovepress.com/testimonials.php to read real quotes from published authors. 